
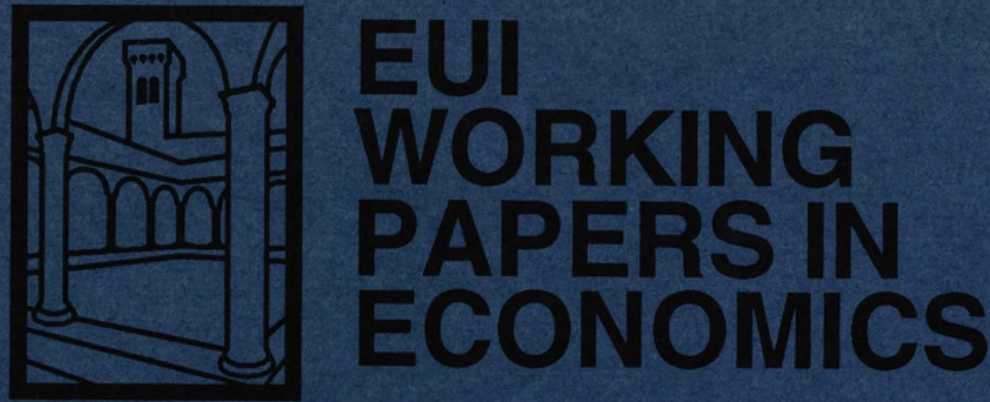

EUI Working Paper ECO No. 93/16

The Effects of Additive Outliers on Tests for Unit Roots and Cointegration

Philip Hans Franses and NiELS HaLdRUP

WEP

330 
EUROPEAN UNIVERSITY INSTITUTE, FLORENCE

ECONOMICS DEPARTMENT

EUI Working Paper ECO No. 93/16

The Effects of Additive Outliers on Tests

for Unit Roots and Cointegration

PHILIP HANS FRANSES and

NIELS HALDRUP 
All rights reserved.

No part of this paper may be reproduced in any form without permission of the authors.

(c) Philip Hans Franses and Niels Haldrup

Printed in Italy in March 1993

European University Institute

Badia Fiesolana

I - 50016 San Domenico (FI)

Italy 


\title{
The Effects of Additive Outliers on Tests for Unit Roots and Cointegration.
}

\author{
by
}

\section{Philip Hans FRANSES,}

Econometric Institute, Erasmus University, Rotterdam, The Netherlands,

and

\begin{abstract}
Niels HALDRUP,
Institute of Economics, University of Aarhus, Denmark, and,

Department of Economics, European University Institute, Florence, Italy.
\end{abstract}

\begin{abstract}
This paper discusses the properties of the univariate Dickey-Fuller test and the Johansen test for the cointegrating rank when there exist additive outlying observations in the time series. The model considered in the paper has some similarities with the classical measurement error model. We provide analytical as well as numerical evidence that additive outliers may produce spurious stationarity. Hence the Dickey-Fuller test will too frequently reject a unit root and the Johansen test will indicate too many cointegrating vectors. Through an empirical example we show how dummy variables can be used to remove this caveat.
\end{abstract}

Keywords: Unit Roots; Additive Outliers; Maximum likelihood cointegration.

JEL Codes: C22; C32.

\section{AUTHORS' NOTES}

This paper was prepared when the first author visited the Institute of Economics in Aarhus in May, 1992 and completed while the second author was a Jean Monnet Fellow at the European University Institute (EUI) in Florence 1992/93. The support from the Royal Dutch Academy of Arts and Sciences is gratefully acknowledged. Comments from participants at the Econometrics Workshop held at the EUI in October 1992 are appreciated; in particular, we would like to thank Andrew Harvey and Agustin Maravall. Thanks are also due to Pierre Perron for kindly providing the data used in the empirical example of the paper. 



\section{INTRODUCTION.}

Testing for unit roots in univariate and multivariate time series has become a standard practice when modelling economic time series. This is because one of the main characteristics of such time series is that they show nonstationary patterns, although there may be occasions in which linear combinations of the series are stationary. In some recent applications as Brodin and Nymoen (1992) and Hendry and Mizon (1990), the modelling strategy is, first, to use the Dickey-Fuller (1979) test to check whether each time series is nonstationary, and, second, to apply the Johansen (1988) maximum likelihood approach to check whether linear combinations of the series are stationary. Given that the time series are nonstationary, the practitioner has to rely on critical values that have been simulated under the assumption of Gaussian error processes.

Besides nonstationarity, other properties of many economic time series are that the variance is time-varying, that there are structural breaks, and that there are outlying (or extreme) observations. Given the underlying assumptions of the generated critical values, it seems worthwhile to investigate whether these additional properties can effect proper practical inference. When the variance process is specified as some kind of an autoregressive conditional heteroscedastic type, it is shown in Kim and Schmidt (1991) and Haldrup (1992) that except from some borderline cases the empirical distributions of unit roots test statistics are generally not much affected. In Franses, Kofman and Moser (1992) it is argued that similar conclusions can be drawn for the multivariate case. The effects of structural breaks, of changing trends, and of innovational outliers are however more severe in some cases. These characteristics are likely to give the impression that a series shows nonstationary behaviour even when it does not contain a unit root, and hence the null hypothesis of a unit root is too easily not rejected. Consequently, it is readily imagined that the critical values for the tests should be modified in this case, see e.g., Perron (1989, 1990), Rappoport and Reichlin (1989), Hendry and Neale (1990), and the 1992-special issue of Journal of Business and Economic Statistics including Banerjee et al. (1992) and Perron and Vogelsang (1992).

In the papers by Perron (1990) and Perron and Vogelsang (1992) additive outliers are considered in the first difference of a time series, that is, under the null of a unit root. The alternative is assumed to be a stationary time series model with a changing mean. Hence, under the null hypothesis there will be a persistent jump in 
the series at the times where outliers occur. In the present paper a different type of additive outliers is considered, namely in the levels of a time series, which is also the most common definition in the literature. Additive outliers of our type affect observations in isolation and may occur as a result of measurement errors or there may be special reasons for their existence. Examples include union-strikes, the hoarding behaviour of consumers when tax changes are announced and the effects of computer breakdowns on registrating, e.g. new car sales or unemployment. Our definition of an additive outlier implies that some shocks will only have a temporary effect and thus, provided they are sufficiently large or sufficiently frequent, may indicate that the series is really stationary. The latter is suggested by the results in Bustos and Yohai (1983) and Martin and Yohai (1986) where it is shown by simulation methods that an additive outlier biases the least squares estimator downward for the parameter in a stationary first order autoregressive process. Ledolter (1989) finds a crude first order approximation to the asymptotic bias in this case. A similar bias will be shown to appear in the nonstationary case. Hence, in some situations it can be expected that the additive outliers will establish the wrong impression that a time series is stationary when it is actually integrated.

The paper follows the following plan. In section 2, we derive an explicit asymptotic expression for the effects of frequency and size implied by additive outliers in case of the univariate Dickey-Fuller test statistic. The Johansen (1988) test method is a multivariate generalisation of this method, and hence we conjecture that similar results will apply for this case. It turns out that the new asymptotic distribution depends linearly on the frequency and on the square of the size of outliers relative to the innovation standard deviation. To verify whether the asymptotic results carry over to small samples, we report the outcomes of some Monte Carlo experiments in section 3. It emerges that even for small sample sizes, some of the asymptotic results closely match the small sample ones. This applies to the univariate as well as for the multivariate case although asymptotic distributions for the latter situation seem to be reached at a less rapid speed when the magnitude of outliers or the probability of outlier occurences is large. In section 4 we show through an empirical example how practical inference can be affected by the presence of additive outliers. The final section concludes the paper with some remarks and with the recommendation that one strategy of avoiding the influence of additive outliers is to include dummy variables in the test equations, provided of course that the outliers have in fact been identified as additive outliers. 


\section{THE MODEL AND SOME ANALYTICAL RESULTS.}

Consider the univariate process

$$
y_{t}=\phi y_{t-1}+\varepsilon_{t} \quad \text { for } t=1,2, \ldots ., T
$$

where for simplicity $\varepsilon_{t}$ is assumed to contain no autocorrelation and suppose that additive outliers of magnitude $\pm \theta$ may occur with a given probability $\pi$. Hence the time series we observe is

$$
z_{t}=y_{t}+\theta \delta_{t}
$$

where $\delta_{t}$ is a Bernoulli variable taking the value 1 or -1 with the specified probability and is zero otherwise. We can also write

$$
\delta_{t}=\delta_{t}^{+}+\delta_{t}^{-}
$$

such that the negative and positive entries of $\delta_{t}$ can be separated and with a probability of a non-zero element in each of $\delta_{t}^{+}$and $\delta_{t}^{-}$being $\pi / 2$. Of course, these will not be independent. Note that even in the case of a unit root in the $y_{t}$-process, $\phi=1$, an additive outlier will only have a temporary effect, since the contamination is added to $y_{t}$. Hence the outlier will produce a once and for all "peak" in the series. This property is very different from innovation outliers, which are defined to be extreme realisations from the process generating the innovations $\varepsilon_{t}$. For the latter situation any shock will have an everlasting influence in the case of a unit root, and will die out gradually when the process is stationary, $|\phi|<1$. An innovation outlier will thus give rise to a "bump" in the series. With respect to testing for unit roots we may expect, however, that additive outliers will be a cause for much greater concern, than innovation outliers, since the latter will affect subsequent observations whereas the former will not. This will rather yield isolated outlier points that are independently located. Note also the importance of defining the additive outlier in the levels of the series and not in the first difference as mentioned in the introduction.

As in the stationary case considered by Bustos and Yohai (1983), Martin and Yohai (1986) and Ledolter (1989), we may expect some bias of the least squares estimator when the time series is not stationary. In figures 1 and 2 the intuition behind this phenomenon is illustrated. In accordance with the above notation figure 1 displays 


\section{Insert Figure 1 about here}

\section{Insert Figure 2 about here}

a scatter plot of $\Delta y_{t}$ on $y_{t-1}$ where $y_{t}$ is a generated random walk of 100 observations with $\varepsilon_{t} \sim N(0,1)$, and $\Delta y_{t}$ is defined by $\Delta y_{t}=y_{t}-y_{t-1}$. In figure 2 outliers have been added to the $y_{t}$ series in agreement with (2.2). The probability of an additive outlier is $\pi=.10$ and $\theta$ is set to 5 . This corresponds to a magnitude of outliers which is 5 times the standard deviation of $\varepsilon_{v}$, which is a very extreme example, of course. The least squares regression line in figure 2 seems to suggest a negative bias of the regression coefficient, i.e. towards rejection of the unit root. When the parameters underlying a model have physical or economic interpretations, the presence of undetected influential observations, like an additive outlier, can therefore mislead the scientist about the properties of the model.

To give an analytical description of the above observation, assume for the case of no outliers that the regression

$$
\Delta y_{t}=\hat{\rho} y_{t-1}+\hat{\varepsilon}_{t}
$$

is conducted where $\rho=\phi-1$. The least squares estimate of $\rho$ is

$$
\hat{\rho}=\left(\sum_{1}^{T} y_{t-1} \Delta y_{t}\right) /\left(\sum_{1}^{T} y_{t-1}^{2}\right)
$$

However, since the time series is observed with additive outliers it follows that

$$
\hat{\rho}_{A O}=\left(\sum_{1}^{T} z_{t-1} \Delta z_{t}\right) /\left(\sum_{1}^{T} z_{t-1}^{2}\right)
$$

and by writing out this expression we obtain

$$
\hat{\rho}_{A O}=\frac{\sum_{1}^{T} y_{t-1} \Delta y_{t}+\theta \sum_{1}^{T} y_{t-1} \Delta \delta_{t}+\theta \sum_{1}^{T} \delta_{t-1} \Delta y_{t}+\theta^{2} \sum_{1}^{T} \delta_{t-1} \Delta \delta_{t}}{\sum_{1}^{T} y_{t-1}^{2}+\theta^{2} \sum_{1}^{T} \delta_{t-1}^{2}+2 \theta \sum_{1}^{T} \delta_{t-1} y_{t-1}} .
$$

The $t$-statistic for a zero coefficient null is defined as

$$
t_{\hat{\rho}_{A O}}=\hat{\rho}_{A O} / \hat{\sigma}\left(\sum_{1}^{T} z_{t-1}^{2}\right)^{-1 / 2}
$$


where

$$
\hat{\sigma}^{2}=T^{-1} \sum_{1}^{T}\left(\Delta z_{t}-\hat{\rho}_{A O} z_{t-1}\right)^{2}
$$

is the squared regression standard error. Further we define

$$
\sigma_{\varepsilon}^{2}=\lim _{T \rightarrow \infty} T^{-1} \sum_{1}^{T} E\left(\varepsilon_{t}^{2}\right)
$$

The limiting behaviour of $\hat{\rho}_{\mathrm{AO}}$ and its t-ratio can now be stated as follows.

\section{PROPOSITION.}

As $T \rightarrow \infty$ we have that

$$
\begin{aligned}
& T \hat{\rho}_{A O} \Rightarrow\left(\int_{0}^{1} W(r) d W\right) /\left(\int_{0}^{1} W^{2}(r) d r\right)-\left(\theta / \sigma_{\varepsilon}\right)^{2} \pi\left(\int_{0}^{1} W^{2}(r) d r\right)^{-1} \\
& t_{\hat{\rho}_{A O}} \Rightarrow\left(1+\left(\theta / \sigma_{\varepsilon}\right)^{2} \pi\right)^{-1 / 2}\left\{\left(\int_{0}^{1} W(r) d W\right) /\left(\int_{0}^{1} W^{2}(r) d r\right)^{1 / 2}-\left(\theta / \sigma_{\varepsilon}\right)^{2} \pi\left(\int_{0}^{1} W^{2}(r) d r\right)^{-1 / 2}\right\}
\end{aligned}
$$

where $" \Rightarrow "$ signifies weak convergence and where $W(r)$ is a standard Brownian Motion defined on the unit interval $r \in[0,1]$.

Proof. See Appendix.

Several interesting results are implied by this proposition. First, the asymptotics show that for either $\pi=0$ or $\theta=0$ the usual Dickey-Fuller distributions as tabulated by Fuller (1976) will apply. Note that for simplicity (but without loss of generality ) we assume there is no weak dependence of the error process $\varepsilon_{t}$ and hence no nuisance parameters entering the limiting distributions for the non-outlier case. If the probability of outlier occurences is strictly positive and $\theta \neq 0, \rho$ is still estimated (super-) consistently, but the limiting distributions contain nuisance parameters and will be shifted to the left and thus the Dickey-Fuller test will have an actual size in excess of the nominal size. Therefore we will reject the unit root hypothesis too often in favour of the stationary alternative. Note also that the distributions are invariant to decompositions of $\left(\theta / \sigma_{\varepsilon}\right)^{2} \pi$ into the single components $\theta, \sigma_{\varepsilon}$, and $\pi$. Some similarities to the standard measurement error model that will generate MA(1) errors are apparent. Observe simply that if additive outliers are sufficiently large and sufficiently frequent, then the error term of $\Delta z_{t}$, i.e. $\varepsilon_{t}+\theta(1-L) \delta_{t}$, will have MA(1)-like 
characteristics which are known to produce nuisance parameters in unit root distributions, see e.g. Schwert (1989) and Pantula (1991).

With respect to the finite sample performance this will of course rely on the relative magnitude of the sample size $T, \pi$ and the magnitude of $\theta$ in relation to $\sigma_{\varepsilon}$. That is, the appropriateness of asymptotic expressions will depend on whether the sample size is sufficiently large to ensure lower order terms in the expression (2.6) to become neglible.

The above results easily generalize to the multivariate case. Johansen (1988, 1991) and Johansen and Juselius (1990) show how for a $p$ 'th order vector autoregressive system the number of stationary (cointegrating) relations $r$, or alternatively, the number of common stochastic trends $p-r$, can be determined. It is shown that the testing procedure amounts to formulating a reduced rank regression problem which can be solved by a simple eigenvalue routine. If the number of cointegrating vectors is $r$, there are $r$ non zero eigenvalues. Testing for the number of cointegrating vectors therefore becomes a matter of testing for the number of zero eigenvalues. Johansen $(1988,1991)$ develops a $L R$-test for the null hypothesis that the $p-r$ smallest eigenvalues will equal zero, i.e. if the eigenvalues in descending order are denoted $\lambda_{1}, \lambda_{2}, \ldots, \lambda_{r}, \ldots, \lambda_{p}$, the so-called trace test for $H_{0}: \lambda_{r+1}=\lambda_{r+2}=\ldots=\lambda_{p}=0$ against the alternative of positive eigenvalues is defined

$$
\lambda_{\text {trace }}=-T \sum_{i=r+1}^{p} \ln \left(1-\hat{\lambda}_{i}\right)
$$

Instead of testing simultaneously the number of cointegrating vectors one could also test $r$ vectors against $r+1, r+1$ vectors against $r+2$ and so forth. Johansen denotes this procedure the $\lambda_{\max }$ test procedure. The above tests have limiting distributions which are straightforward generalisations of the univariate Dickey-Fuller test to the multivariate case. In terms of asymptotics a univariate Brownian Motion process $W(r)$ is replaced by a vector Brownian Motion process, but otherwise the distributions are very similar. Empirical fractiles are tabulated in Johansen and Juselius (1990). It is therefore our conjecture that the results from the univariate model will carry over in a straightforward manner to the multivariate $\lambda_{\text {trace }}$ and $\lambda_{\max }$ tests.

\section{NUMERICAL EVIDENCE.}

In this section we provide some Monte Carlo evidence in order to illustrate the 
practical implications of our analytical findings. The set-up of our experiments follows the notation used in the previous section. For the univariate case the data were generated according to (2.1) and (2.2) with $\varepsilon_{i} \sim N(0,1)$, i.e. $\sigma_{\varepsilon}^{2}=1$, and the experimental design included $\theta=\{0,3,4,5\}, \pi=\{.05, .10\}$ and $T=\{25,100,400\}$. The regression model was

$$
\Delta z_{t}=\hat{\rho}_{A O} z_{t-1}+\hat{\varepsilon}_{t}
$$

from which the $t$-ratio was calculated as in (2.7). Inclusion of deterministic regressors in the auxiliary Dickey-Fuller regressions will affect the distributions, of course, but in order to focus on additive outliers only, the model with no deterministics provides a satisfactory simplification in this case. For the Dickey-Fuller regression results are reported in table 1 .

With respect to the Johansen test we considered a first order bivariate VARsystem of non-cointegrated time series. Both series were generated as above and the same parameter space as in the univariate case was analyzed. In each experiment both series contained the same probability of outlier occurences and the value of $\theta$, the magnitude of outliers, were the same. However, the location of additive outliers were different by construction. Fractiles for the two lamda-max tests and the trace test statistics are reported in tables 2, 3 and 4, respectively. In all simulations 10000 replicates were used to construct the fractiles. See tables 2 and 3 for a detailed description of how the empirical distributions were generated.

The simulation experiments closely mimic our analytical findings. In fact, the change in distribution is quite dramatic in some cases when both the outlier probability and the magnitude of outliers become large. Of course this is of no surprise since the contribution to the total variation resulting from the outliers becomes relatively influential when both $\pi$ and $\theta$ increase, despite their temporary effect. Hence the signal from the random walk component will be annihilated by the noise from the outliers as these two parameters increase in magnitude. With respect to the fractiles of the univariate Dickey-Fuller test a probability of an outlier of $\pi=.05$, $\theta=3$ standard deviations, and a sample size of $T=100$ corresponds to an actual size of the test equal to .181 at a nominal $5 \%$ level.

\section{Insert Table 1 about here \\ Insert Figure 3 about here}


When $\pi$ increases to $\pi=.10$ the size is .269 and detoriates even more as the magnitude of outliers increases. Note that our asymptotic results suggest empirical fractiles to be similar when $\left(\theta / \sigma_{\varepsilon}\right)^{2} \pi$ attains the same value $K$ for a given experiment. If for instance $(\pi=.05, \theta=4)$ and $(\pi=.10, \theta=3)$ then $K=.8$ and $K=.9$, respectively, and the fractiles appear to be very similar. We also constructed other experiments where $K$ attained the same value and, indeed, the simulated distributions appeared to be almost identical even in small samples. In figure 3 the empirical density functions for the DickeyFuller $t$-test are displayed for a sample size of $T=100$ for $K=0$, (i.e. the Dickey-Fuller distribution) and $K=.75$, and 1.5 respectively.

Concerning the Johansen tests many of the conclusions from the univariate model apply. All three tests entail huge shifts in the distributions as $\theta$ and $\pi$ increase, however, size distortions are generally worse in comparison with the Dickey-Fuller test. We will too frequently accept cointegration, i.e. the case of strictly positive eigenvalues. The results concerning a fixed value of $K$ also apply in the multivariate model. One respect in which the Johansen tests seem to differ from the Dickey-Fuller test is the rate by which empirical distributions will tend to their limiting distributions. If either $\theta$ and/or $\pi$ is of great magnitude there are huge differences between the empirical distributions for a small sample size and the empirical distributions for a large sample size, 400 say. However, we provided further evidence by increasing the number of observations and it appeared that there would only be a slight change in distributions in relation to those reported for $T=400$. In fact, the distributions for $T=1600$ were quite close to those reported for $T=400$. These results can be obtained from the authors upon request. The above observation seems to suggest, that for $\theta, \pi$ "large" there may still exist elements in the distributions that are not neglible in finite samples although these elements will be of a lower order and in the limit will vanish. In the above experiments the outliers are dated at different points in time for each series. We may expect, however, that if the dating of additive outliers is the same for each series then the influence on the empirical distributions will be very small,probably there will no observable change in the distributions at all.

\section{Insert Table 2 about here}

\section{Insert Table 3 about here}

\section{Insert Table 4 about here}




\section{AN EMPIRICAL EXAMPLE}

In order to illustrate our analytical findings by an empirical example we considered the data set analyzed by Perron and Vogelsang (1992). The time series are the U.S./Finland real-exchange rate series based on both the CPI index and the GDP deflator. The data is annual and cover the periods 1900-1988 and 1900-1987, respectively. The series are displayed in figures 4 and 6. Perron and Vogelsang used the data in order to examine whether the time series were better described as stationary time series with a changing mean rather than integrated or unit root processes. By conducting an augmented Dickey-Fuller (ADF) test they found a $t$-ratio of -5.74 when the CPI measure was used with $p=1$ lag of the differenced series included in the auxiliary regression $(5 \%$ critical value $=-2.89)$. Hence, the unit root hypothesis was rejected for this series. On the contrary, when using the GDP deflator to define the real exchange rate the ADF-test with $p=2$ gave a test value of -1.62 , thus accepting a unit root. Perron and Vogelsang challenged the view that the latter series was really a unit root process and showed by methods developed in the paper, that by allowing for a one-time change in the mean, the series was better described as being stationary.

Now, visual inspection of the charts 4 and 5 seems to indicate that both series, may, in fact, contain additive outlying observations. Spikes are observed in both series for 1918, 1921, 1932, 1948 and 1949. A minor spike is also observed in 1945. All the data irregularities have the characteristics of being additive outliers, since the series returns to the original level of the series after the extreme observation is observed. There also seem to be some intuitive reasons for the outliers, i.e. World War I, the crisis in the thirties, and the turbulence following World War II. Especially for the CPI-based measure a huge spike is observed in 1918, which may give a wrong impression of the scale of the $y$-axes. In figure 6, the years 1917-1919 have been removed from the series, and by so doing the impact of the remaining outliers become even more clear-cut.

In regression models additive outliers will normally show up in the residuals and give rise to a high kurtosis coefficient. The Jarque-Bera test for normality following from the regressions reported by Perron and Vogelsang give test values 835.67 and 26.83 , respectively, which should be compared with fractiles from a $\chi^{2}(2)$ distribution. Of course the normality of the regression residuals is strongly rejected. Several methods can be used to cope with the presence of additive outliers. One 
method is to consider robust estimation of the model by attaching less weight to extreme observations. How this will affect unit root inference is not yet clear. A different approach is to simply remove the outlier and treat the observation as a missing value. Maravall and Peña (1992) show how even for nonstationary time series the estimation of a missing value can be conducted by the Kalman filter smoother. For illustrative purpose we follow a much simpler pragmatic route by simply including dummy-variables in the auxiliary ADF-regression. It can be shown that the inclusion of impulse dummies will not affect the limiting distributions of the test statistics although the effective sample size when dealing with a fixed span of data may be reduced. Naturally this may cause minor changes in the finite sample distributions, if sufficiently many outliers are present.

The regression we suggest to conduct is of the form

$$
\Delta z_{t}=(\alpha-1) z_{t-1}+\sum_{i-0}^{p} \sum_{j-1}^{k} \omega_{i j} D_{t-i}^{j}+\sum_{i-1}^{p} \psi_{i} \Delta z_{t-i}+e_{t}
$$

where we then test whether $(\alpha-1)=0$ using the ADF- $t$-ratio. Of course a trend may be included in the regression as well. Note that for each impulse dummy variable, $D^{j}$, taking the value 1 at time $j, p$ lags should be included since the presence of lagged differences by construction will entail "lagged" additive outliers.

With respect to the CPI-based real exchange rate we included dummy variables corresponding to the peaks previously discussed and lags hereof. For $p=2$ lags in the regression model and by excluding the most insignificant dummies (i.e. effectively including $D^{17}-D^{19}, D^{32}, D^{33}, D^{45}, D^{49}, D^{50}$ ) we obtained ADF=-2.65 whereby the null hypothesis is now not rejected. The estimate of the AR-root increased from .49 to .81 by including the dummy variables and the Jarque-Bera test value dropped to 12.63 indicating that the influence from outliers had been reduced considerably. We also conducted the same regression as above to the GDP based measure and obtained a Dickey-Fuller test value of -1.03 , i.e. giving even stronger evidence for the presence of a unit root. The root estimate itself increased from .91 to .96.

As seen from our example the analytical findings are supported by the data. Whether the resulting time series are better described to be stationary with a changing mean is of course a different question. In fact, the nonstationarity of real exchange rate series has far reaching economic consequences, i.e. PPP not holding in the long run, so the alternative suggested by Perron and Vogelvang is probably right at the point. Notwithstanding our empirical application has illustrated another example of the 
modesty by which the results from unit root tests should be interpreted.

\section{CONCLUSIONS.}

In the literature it is often argued that outlying observations and structural breaks may produce time series that are easily interchanged with unit root processes. This paper addresses a different kind of time series, namely processes with additive influential observations, and as shown the implications of this type of data irregularities will tend to produce spurious stationarity as opposed to the situations described above. The analytical and numerical results reported in the paper were based on the assumption that additive outliers of a certain magnitude will appear randomly with a given probability. Other descriptions of how additive outliers may occur can be considered but generally we may expect similar results. For instance, it is frequently observed that seasonal time series have a very strong (deterministic) pattern which, effectively, makes the seasonal variation of the data of a larger magnitude than the zero frequency variation of the data, at least for a finite stretch of data. The seasonal pattern in this case could therefore correspond very much to additive outliers of a deterministic kind, i.e. like when we model seasonality using dummy variables.

Although the use of dummy variables may at first sight appear a little arbitrary, it is extremely important to provide good economic interpretations for the particular dummy variables that appear to be required or at least one should find some reasons for the irregularities observed to avoid ad hoc-ness. If the removal of an additive outlier is done by including a dummy variable in the regression model it can be shown that this will remove the influence from the outlier and thus give rise to distributions under the null with a controllable size. However, the effective sample size will be reduced of course, which may affect the finite sample distributions. Alternatively we may replace outlying observations by those fitted using the procedures considered by Maravall and Peña (1992). As opposed to time series models with structural changes, changing means or regime shifts, say, there are no pretesting problems when additive outliers are considered, at least as long not too many additive outliers are present, see e.g. Perron (1991), Perron and Vogelsang (1992) and Zivot and Andrews for a discussion of pretesting problems.

In practice, innovation outliers and structural breaks are probably more frequently observed than additive outliers. However, the message of our paper is that outliers of any kind may invalidate inference when analyzing univariate and 
multivariate time series models, and a careful detection and treatment of the outliers is therefore very important. Our findings also indicate the fragility of results from unit root tests. Testing for unit roots will only provide simple approximate formula for the basic properties of an observed time series. More fundamentally, the presence of outlying observations may indicate that a univariate model is inappropriate. This is also why a multivariate analysis including many explanatory variables may partially solve the problem, i.e. if the extreme observations occur jointly amongst the series and can be expected to cancel out when the simultaneous system is modelled. 
APPENDIX.

Proof of PROPOSITION.

The least squares estimator in case of additive outliers reads

$$
\hat{\rho}_{A O}=\frac{\sum_{1}^{T} y_{t-1} \Delta y_{t}+\theta \sum_{1}^{T} y_{t-1} \Delta \delta_{t}+\theta \sum_{1}^{T} \delta_{t-1} \Delta y_{t}+\theta^{2} \sum_{1}^{T} \delta_{t-1} \Delta \delta_{t}}{\sum_{1}^{T} y_{t-1}^{2}+\theta^{2} \sum_{1}^{T} \delta_{t-1}^{2}+2 \theta \sum_{1}^{T} \delta_{t-1} y_{t-1}} .
$$

With respect to the order of magnitude of the terms entering the expression we have the following Lemma:

LEMMA. As $T \rightarrow \infty$

(a)

(b) $\quad T^{-2} \sum_{1}^{T} y_{t-1}^{2} \Rightarrow \sigma_{\varepsilon}^{2} \int_{0}^{1} W^{2}(r) d r$

(c) $T^{-1} \sum_{1}^{T} \delta_{t-1}^{2} \Rightarrow \pi$

(d) $\quad T^{-1} \sum_{t-1}^{T} \delta_{t-1} \Delta \delta_{t}=-T^{-1} \sum_{1}^{T} \delta_{t-1}^{2}+T^{-1} \sum_{1}^{T} \delta_{t-1} \delta_{t} \Rightarrow-\pi$

(e) $\quad T^{-1 / 2} \sum_{1}^{T} \delta_{t-1} \Delta y_{t}=T^{-1 / 2} \sum_{1}^{T} \delta_{t-1} \varepsilon_{t}=o_{p}(1)$

for $0<\pi<1$

(f) $\quad T^{-3 / 2} \sum_{1}^{T} \delta_{t-1} y_{t-1}=o_{p}(1)$

for $0<\pi<1$

(g)

$$
T^{-1 / 2} \sum_{1}^{T} y_{t-1} \Delta \delta_{t}=T^{-1 / 2} \sum_{1}^{T} \delta_{t} \varepsilon_{t-1}=o_{P}(1)
$$

for $0<\pi<1$

Proof. For those familiar with the work by Phillips (1987) and his co-authors, (a) and (b) are obvious. Note however that no non-centrality parameters enter in (a) since for simplicity we have assumed innovations to be iid. (c) tells us that in the limit the number of non-zero entries in the dummy variable divided by the number of observations tends to the probability of an additive outlier occurence. For (d) the second term on the RHS of the equality sign tends to zero as $T \rightarrow \infty$ which follows from a symmetry argument. Note simply that in accordance with the notation in the main text $\mathrm{E}\left(\delta_{t} \delta_{t-1}\right)=\lim _{T \rightarrow \infty} T^{-1} \sum_{1}^{T} \delta_{t} \delta_{t-1}=\mathrm{E}\left(\left(\delta_{t^{+}}{ }^{+} \delta_{t}{ }^{-}\right)\left(\delta_{t-1}{ }^{+}+\delta_{t-1}{ }^{-}\right)\right)=(\pi / 2)^{2}-(\pi / 2)^{2}{ }^{-}$ $(\pi / 2)^{2}+(\pi / 2)^{2}=0$. For (e), (f) and (g) it holds that in case $\pi=1$ the orders of magnitude will be $O_{p}(1)$ which will set an upper limit for the expressions. In case $0<\pi<1$ elements of the stochastic series will be picked out and the orders will be of a lesser magnitude. 
Now it follows that

$$
\begin{aligned}
T \hat{\rho}_{A O}= & \frac{T^{-1} \sum_{1}^{T} y_{t-1} \Delta y_{t}+\theta^{2} T^{-1} \sum_{1}^{T} \delta_{t-1} \Delta \delta_{t}+o_{p}(1)}{T^{-2} \sum_{1}^{T} y_{t-1}^{2}+o_{p}(1)} \Rightarrow \\
& \left(\int_{0}^{1} W(r) d W\right) /\left(\int_{0}^{1} W^{2}(r) d r\right)-\left(\theta / \sigma_{\varepsilon}\right)^{2} \pi\left(\int_{0}^{1} W^{2}(r) d r\right)^{-1}
\end{aligned}
$$

Concerning the $t$-ratio as defined in (2.7) we have that

$$
\begin{aligned}
\hat{\sigma}^{2} & =T^{-1} \sum_{1}^{T}\left(\Delta z_{t}-\hat{\rho} z_{t-1}\right)^{2} \\
& =T^{-1} \sum_{1}^{T}\left(\Delta y_{t}+\theta \Delta \delta_{t}-\hat{\rho} y_{t-1}-\theta \delta_{t-1}\right)^{2} \\
& =T^{-1} \sum_{1}^{T} \varepsilon_{t}^{2}+\theta^{2} \pi+o_{p}(1) \\
& \Rightarrow \sigma_{\varepsilon}^{2}+\theta^{2} \pi .
\end{aligned}
$$

It is also easily verified that

$$
T^{-2} \sum_{1}^{T} z_{t-1}^{2}=T^{-2} \sum_{1}^{T}\left(y_{t-1}+\theta \delta_{t-1}\right)^{2}=T^{-2} \sum_{1}^{T} y_{t-1}^{2}+o_{p}(1) \Rightarrow \sigma_{\varepsilon}^{2} \int_{0}^{1} W^{2}(r) d r
$$

such that by direct application of these results to (2.7) we get the desired results. 


\section{TABLES.}

TABLE 1. Empirical Fractiles for the univariate Dickey-Fuller t-test. Based on 10000 replications.

\begin{tabular}{|c|c|c|c|c|c|c|c|}
\hline$\pi$ & $\theta$ & $T$ & .01 & .025 & .05 & .10 & $5 \%$-Size \\
\hline \multirow{3}{*}{0} & & 25 & -2.66 & -2.26 & -1.95 & -1.60 & .050 \\
\hline & & 100 & -2.60 & -2.24 & -1.95 & -1.61 & .050 \\
\hline & & 400 & -2.58 & -2.23 & -1.95 & -1.62 & .050 \\
\hline \multirow{9}{*}{.05} & \multirow{3}{*}{3} & 25 & -3.75 & -3.20 & -2.76 & -2.27 & .142 \\
\hline & & 100 & -3.65 & -3.14 & -2.75 & -2.32 & .181 \\
\hline & & 400 & -3.70 & -3.15 & -2.78 & -2.36 & .174 \\
\hline & \multirow{3}{*}{4} & 25 & -4.20 & -3.59 & -3.17 & -2.63 & .255 \\
\hline & & 100 & -4.38 & -3.78 & -3.26 & -2.74 & .264 \\
\hline & & 400 & -4.29 & -3.77 & -3.24 & -2.74 & .353 \\
\hline & \multirow{3}{*}{5} & 25 & -4.62 & -4.01 & -3.49 & -2.97 & .270 \\
\hline & & 100 & -4.89 & -4.20 & -3.72 & -3.13 & .332 \\
\hline & & 400 & -4.96 & -4.30 & -3.81 & -3.24 & .355 \\
\hline \multirow{9}{*}{.10} & \multirow{3}{*}{3} & 25 & -4.17 & -3.65 & -3.21 & -2.69 & .237 \\
\hline & & 100 & -4.35 & -3.80 & -3.37 & -2.85 & .269 \\
\hline & & 400 & -4.50 & -3.81 & -3.34 & -2.83 & .279 \\
\hline & \multirow{3}{*}{4} & 25 & -4.79 & -4.23 & -3.70 & -3.18 & .353 \\
\hline & & 100 & -5.13 & -4.55 & -4.00 & -3.40 & .385 \\
\hline & & 400 & -5.43 & -4.76 & -4.17 & -3.57 & .424 \\
\hline & \multirow{3}{*}{5} & 25 & -5.09 & -4.53 & -4.05 & -3.50 & .454 \\
\hline & & 100 & -6.01 & -5.39 & -4.77 & -4.11 & .489 \\
\hline & & 400 & -6.36 & -5.61 & -4.95 & -4.27 & .529 \\
\hline
\end{tabular}

NOTE. The sizes reported are actual sizes at a nominal 5\%-level.

The fractiles were calculated as follows. Univariate time series were generated in accordance with (2.1) and (2.2) by letting $\sigma_{\varepsilon}^{2}=1$. Next the Dickey-Fuller regression with no deterministics was generated from which the $t$-ratio, (2.7), was calculated. For each sample size and each value of the design parameters the test-statistics were calculated and replicated 10000 times. 
TABLE 2. Empirical Fractiles for the Johansen $\lambda_{\text {max- } 1}$ test. Based on 10000 replications.

\begin{tabular}{|c|c|c|c|c|c|c|c|}
\hline$\pi$ & $\theta$ & $T$ & .90 & .95 & .975 & .99 & $5 \%$-size \\
\hline \multirow{3}{*}{0} & & 25 & 6.96 & 8.94 & 11.00 & 13.67 & .050 \\
\hline & & 100 & 6.61 & 8.33 & 10.06 & 11.79 & .050 \\
\hline & & 400 & 6.62 & 8.29 & 10.00 & 11.89 & .050 \\
\hline \multirow{9}{*}{.05} & \multirow{3}{*}{3} & 25 & 10.24 & 13.26 & 16.66 & 21.24 & .137 \\
\hline & & 100 & 10.69 & 13.41 & 16.20 & 20.36 & .175 \\
\hline & & 400 & 10.84 & 13.60 & 16.48 & 19.94 & .194 \\
\hline & \multirow{3}{*}{4} & 25 & 12.67 & 16.52 & 20.77 & 25.94 & .211 \\
\hline & & 100 & 14.20 & 18.06 & 21.81 & 26.97 & .291 \\
\hline & & 400 & 14.14 & 17.58 & 21.41 & 25.90 & .307 \\
\hline & \multirow{3}{*}{5} & 25 & 15.26 & 19.45 & 23.61 & 29.90 & .288 \\
\hline & & 100 & 17.68 & 22.46 & 26.98 & 32.33 & .410 \\
\hline & & 400 & 18.65 & 23.60 & 28.14 & 35.07 & .437 \\
\hline \multirow{9}{*}{.10} & \multirow{3}{*}{3} & 25 & 12.89 & 16.52 & 20.04 & 25.39 & .221 \\
\hline & & 100 & 14.79 & 18.65 & 22.56 & 28.02 & .327 \\
\hline & & 400 & 15.62 & 19.33 & 23.41 & 27.84 & .351 \\
\hline & \multirow{3}{*}{4} & 25 & 16.75 & 20.67 & 25.03 & 30.00 & .345 \\
\hline & & 100 & 20.85 & 25.56 & 30.85 & 37.69 & .486 \\
\hline & & 400 & 22.19 & 27.59 & 32.76 & 39.80 & .522 \\
\hline & \multirow{3}{*}{5} & 25 & 19.53 & 24.47 & 29.39 & 35.07 & .438 \\
\hline & & 100 & 26,75 & 32.83 & 38.84 & 46.25 & .635 \\
\hline & & 400 & 31.16 & 39.26 & 47.30 & 56.70 & .688 \\
\hline
\end{tabular}

NOTE: The sizes reported are actual sizes at a nominal 5\%-level.

The fractiles were calculated as follows. The $\lambda_{\max -1}$ test is constructed under the assumption of a first order system. Since the LR-test in this case is the squared $t$-ratio of the Dickey-Fuller test we generated data series in accordance with (2.1) and (2.2) such that $\sigma_{\varepsilon}^{2}$ and constructed the squared $t$-ratio as in (2.7). However, to facilitate comparison with the Johansen and Juselius (1990), Table A2 p. 208, a constant was included in the auxiliary regression. For each sample size and each value of the design parameters the test statistics were calculated and replicated 10000 times. 
TABLE 3. Empirical Fractiles for the Johansen $\lambda_{\max -2}$ test. Based on 10000 replications.

\begin{tabular}{|c|c|c|c|c|c|c|c|}
\hline$\pi$ & $\theta$ & $T$ & .90 & .95 & .975 & .99 & $5 \%$-size \\
\hline \multirow{3}{*}{0} & & 25 & 13.48 & 15.40 & 17.30 & 19.67 & .050 \\
\hline & & 100 & 13.14 & 15.18 & 16.95 & 19.36 & .050 \\
\hline & & 400 & 13.09 & 15.01 & 16.72 & 18.95 & .050 \\
\hline \multirow{9}{*}{.05} & \multirow{3}{*}{3} & 25 & 16.75 & 19.31 & 21.65 & 24.40 & .147 \\
\hline & & 100 & 18.85 & 21.74 & 24.67 & 28.28 & .217 \\
\hline & & 400 & 19.58 & 22.75 & 25.63 & 29.73 & .244 \\
\hline & \multirow{3}{*}{4} & 25 & 18.55 & 21.08 & 23.46 & 26.30 & .210 \\
\hline & & 100 & 23.47 & 26.95 & 30.41 & 34.40 & .382 \\
\hline & & 400 & 25.36 & 29.55 & 33.42 & 39.05 & .457 \\
\hline & \multirow{3}{*}{5} & 25 & 19.98 & 22.98 & 25.70 & 28.94 & .281 \\
\hline & & 100 & 28.19 & 32.29 & 35.96 & 40.68 & .543 \\
\hline & & 400 & 33.04 & 38.47 & 43.04 & 50.18 & .651 \\
\hline \multirow{9}{*}{.10} & \multirow{3}{*}{3} & 25 & 18.64 & 21.13 & 23.53 & 26.70 & .220 \\
\hline & & 100 & 24.30 & 27.98 & 30.88 & 35.23 & .413 \\
\hline & & 400 & 27.13 & 31.22 & 35.13 & 39.95 & 489 \\
\hline & \multirow{3}{*}{4} & 25 & 20.86 & 23.45 & 25.88 & 28.88 & .322 \\
\hline & & 100 & 31.29 & 35.90 & 39.67 & 44.78 & .664 \\
\hline & & 400 & 38.28 & 44.30 & 50.79 & 57.65 & .759 \\
\hline & \multirow{3}{*}{5} & 25 & 22.64 & 25.13 & 27.58 & 30.44 & .449 \\
\hline & & 100 & 37.59 & 42.53 & 46.77 & 51.55 & .842 \\
\hline & & 400 & 51.20 & 58.73 & 65.96 & 74.80 & .899 \\
\hline
\end{tabular}

NOTE: The sizes reported are actual sizes at a nominal 5\%-level.The fractiles were generated as follows. A bivariate time series of first order was generated in accordance with (2.1) and (2.2) for each series and with $\varepsilon_{i t} \sim N(0,1), i=1,2, . \quad \varepsilon_{1 t}$ and $\varepsilon_{2 t}$ are uncorrelated temporarily as well as contemporaneously. For simplicity we ignored conditioning on short run dynamics in the estimation due to the assumption of a first order system, but the series were demeaned to facilitate comparison with the fractiles reported by Johansen and Juselius (1990), table A2 p. 208. Following the notation of Johansen we let $X_{t}=\left(x_{1 t}, x_{2}\right)$ and define $R_{0 t}=\Delta X_{t}^{*}, R_{1 t}=X_{t-1}^{*}$ where a '*' indicates that the series have been demeaned. Next the moment matrices $S_{i j}=T^{-l} \Sigma_{T}^{T} R_{i j} R_{j t}$ for $i, j=0,1$ are calculated. If the VAR-model is written in ECM-form $\Delta X_{t}=\mu+\alpha \beta^{\prime} X_{t-1}+e_{t}$ the (reduced) rank of the matrix $\Pi=\alpha \beta$ ' is found by solving the eigenvalue problem $\left|\lambda S_{11}-S_{10} S_{00}^{-1} S_{01}\right|=0$ which gives the eigenvalues $\lambda_{1}, \lambda_{2}$ in ascending order. The test-statistics are now easily constructed as

$$
\lambda_{\max }=-T \ln \left(1-\hat{\lambda}_{2}\right) \quad \lambda_{\text {trace }}--T \ln \left(1-\hat{\lambda}_{1}\right)-T \ln \left(1-\hat{\lambda}_{2}\right)
$$

For each sample size and each value of the design parameters the test-statistics were calculated and replicated 10000 times. 
TABLE 4. Empirical Fractiles for the Johansen $\lambda_{\text {trace }}$ test. Based on 10000 replications.

\begin{tabular}{|c|c|c|c|c|c|c|c|}
\hline$\pi$ & $\theta$ & $T$ & .90 & .95 & .975 & .99 & $5 \%$-size \\
\hline \multirow{3}{*}{0} & & 25 & 16.21 & 18.60 & 20.77 & 23.27 & .050 \\
\hline & & 100 & 15.98 & 18.21 & 20.48 & 22.95 & .050 \\
\hline & & 400 & 15.91 & 18.38 & 20.01 & 22.85 & .050 \\
\hline \multirow{9}{*}{.05} & \multirow{3}{*}{3} & 25 & 20.51 & 23.24 & 25.93 & 29.35 & .148 \\
\hline & & 100 & 22.69 & 26.08 & 29.49 & 33.70 & .238 \\
\hline & & 400 & 23.55 & 27.17 & 30.50 & 33.92 & .255 \\
\hline & \multirow{3}{*}{4} & 25 & 22.93 & 26.04 & 28.77 & 31.94 & .222 \\
\hline & & 100 & 28.35 & 32.53 & 36.21 & 40.73 & .416 \\
\hline & & 400 & 30.71 & 35.21 & 39.46 & 45.46 & .474 \\
\hline & \multirow{3}{*}{5} & 25 & 25.12 & 28.87 & 31.93 & 35.92 & .590 \\
\hline & & 100 & 34.66 & 39.16 & 43.75 & 49.29 & .691 \\
\hline & & 400 & 39.94 & 45.94 & 52.19 & 57.93 & .569 \\
\hline \multirow{9}{*}{.10} & \multirow{3}{*}{3} & 25 & 23.32 & 26.12 & 28.93 & 32.36 & .259 \\
\hline & & 100 & 29.51 & 33.71 & 37.72 & 42.11 & .477 \\
\hline & & 400 & 32.59 & 37.40 & 41.96 & 47.95 & .517 \\
\hline & \multirow{3}{*}{4} & 25 & 26.67 & 29.73 & 32.48 & 36.09 & .398 \\
\hline & & 100 & 38.96 & 44.37 & 48.82 & 54.63 & .723 \\
\hline & & 400 & 46.31 & 53.05 & 59.65 & 68.94 & .803 \\
\hline & \multirow{3}{*}{5} & 25 & 29.46 & 32.67 & 35.70 & 39.45 & .569 \\
\hline & & 100 & 48.06 & 53.97 & 59.52 & 65.57 & .891 \\
\hline & & 400 & 62.31 & 70.73 & 80.15 & 90.27 & .930 \\
\hline
\end{tabular}

NOTE: See table 3. 


\section{FIGURES}

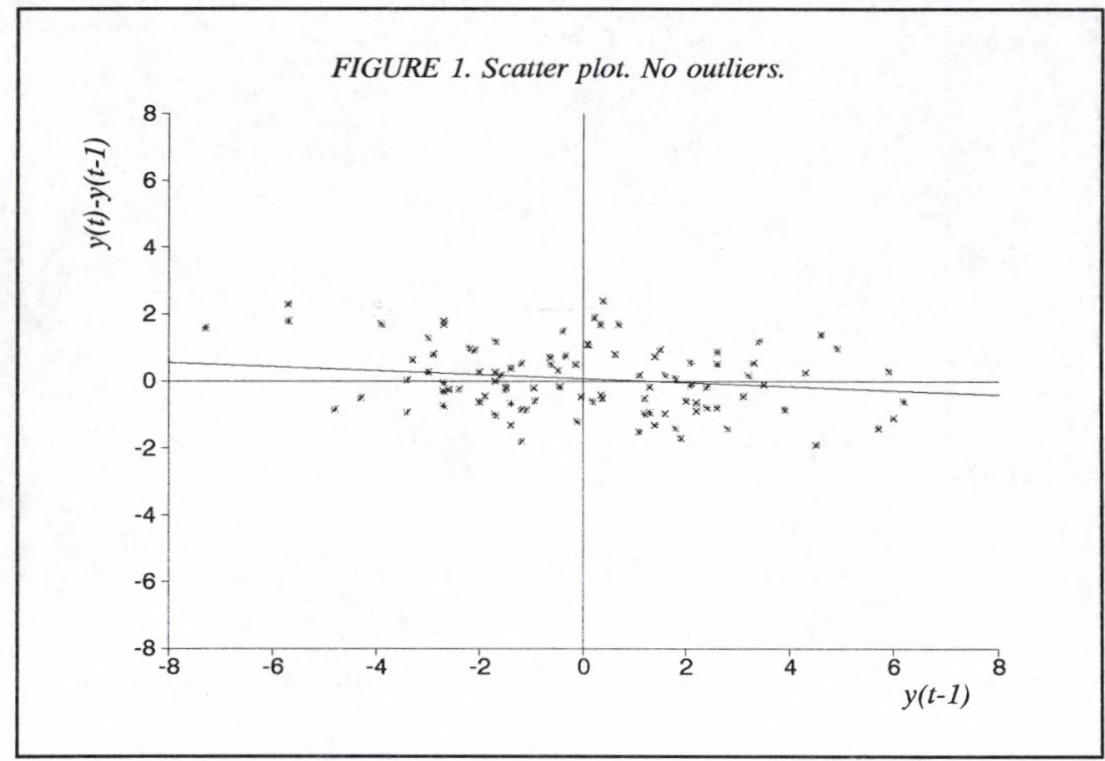

FIGURE 2. Scatter plot. Additive outliers.

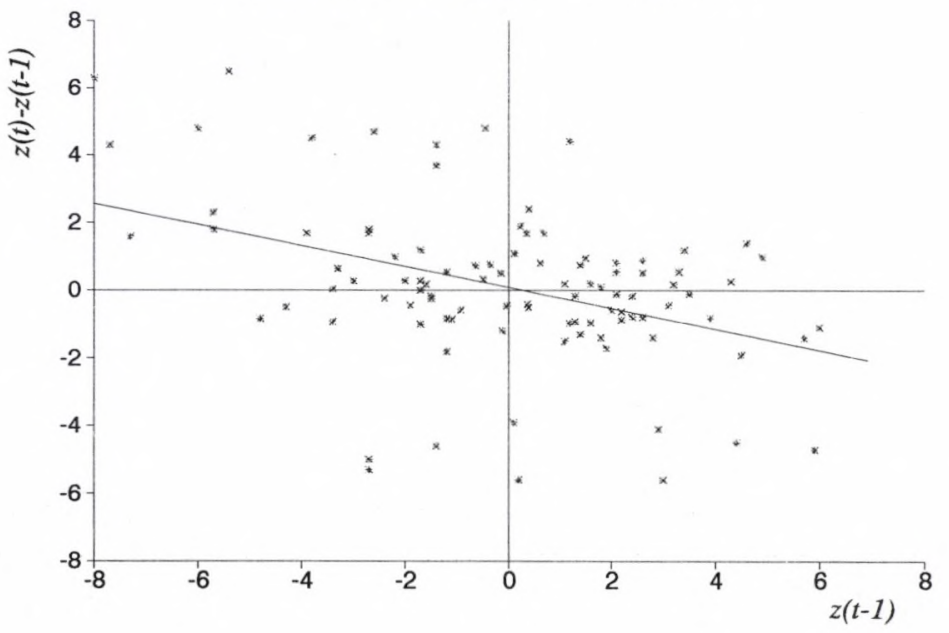


FIGURE 3. Density Functions for Dickey-Fuller t-test.

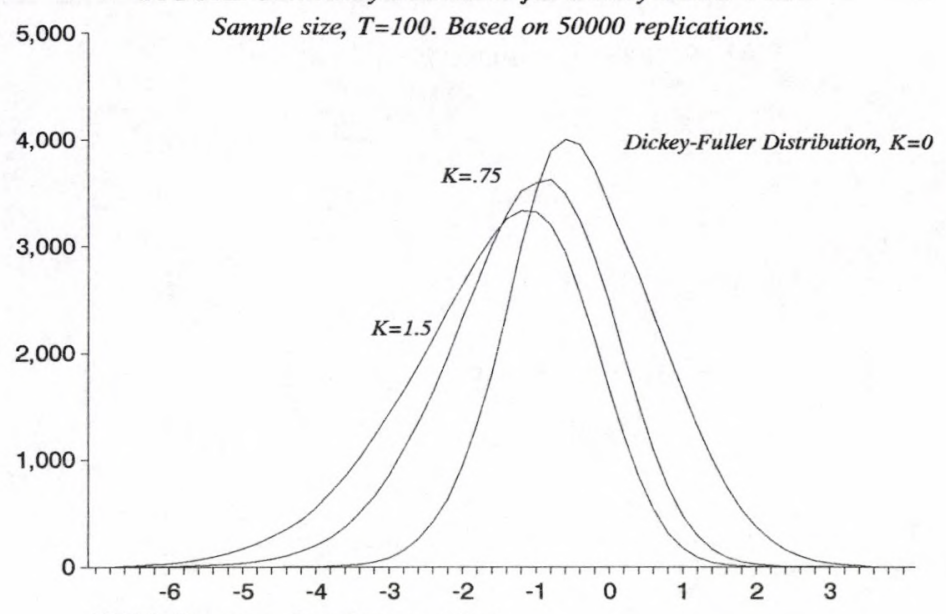

NOTE: The curves have been smoothed. 
FIGURE 4. Logarithm of the U.S./Finland Real Exchange Rate Based on the Consumer Price Indexes (CPI); 1900-1988, Annual.

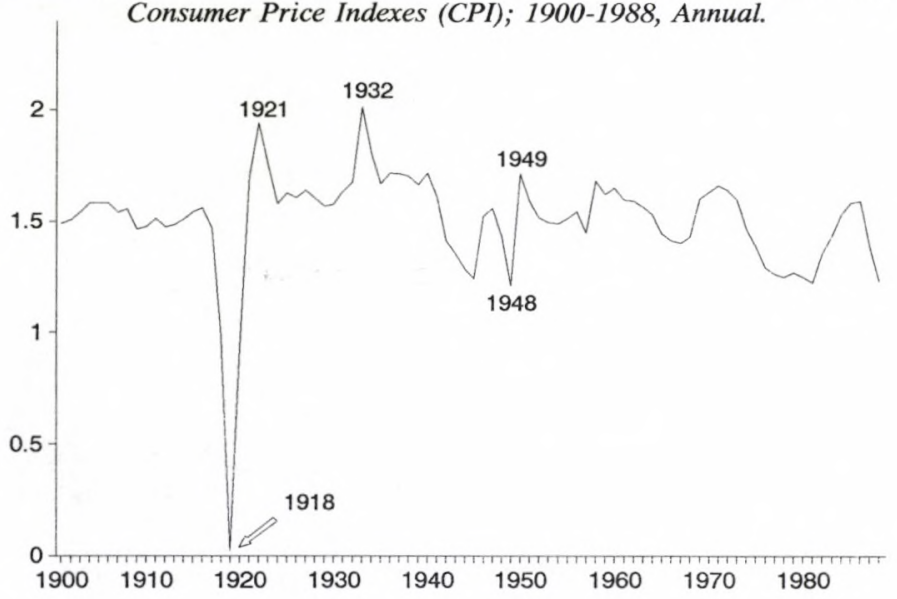

FIGURE 5. Logarithm of the U.S./Finland Real Exchange Rate Based on the GNP (GDP) Deflators as the Price Indexes; 1900-1987, Annual.

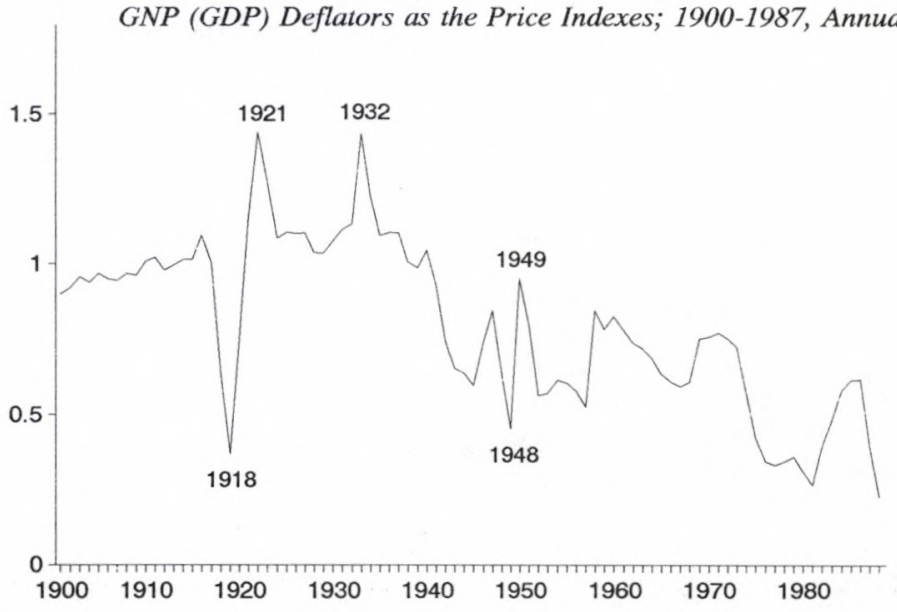


FIGURE 6. Logarithm of the U.S./Finland Real Exchange Rate Based on the 2.3 Consumer Price Indexes (CPI); 1900-16, 1920-88, Annual.

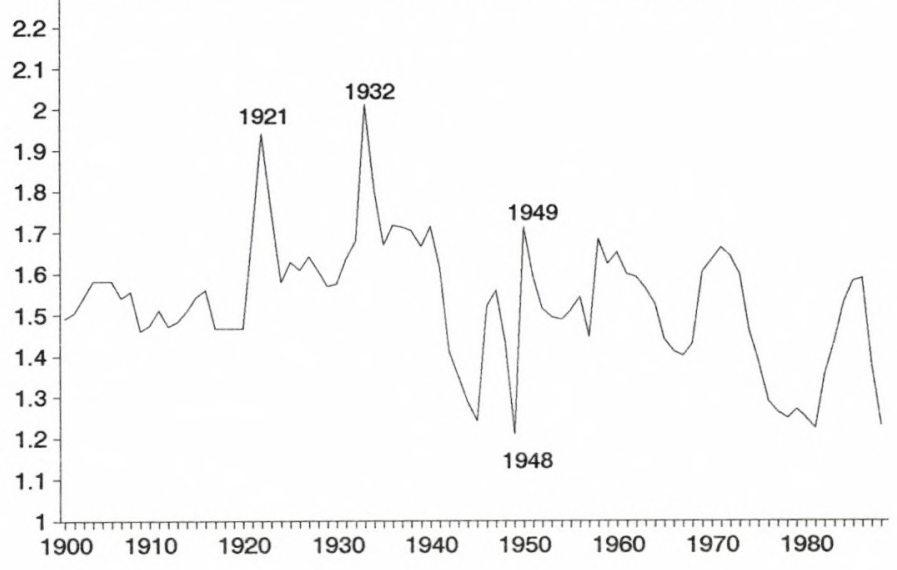




\section{REFERENCES}

Banerjee, A., R.L.Lumsdaine, and J.H.Stock, 1992. Recursive and Sequential Tests of the Unit Root and Trend Break Hypothesis: Theory and International Evidence. Journal of Business and Economic Statistics, 10, pp. 271-287.

Brodin A. and R. Nymoen, 1992. Wealth Effects and Exogeneity: The Norwegian Consumption Function 1966(1)-1984(4). Oxford Bulletin of Economics and Statistics, 54, pp. 431-455.

Bustos, O. H. and V. J. Yohai, 1986. Robust estimates for ARIMA models, Journal of the American Statistical Association, 81, pp. 155-168.

Clements, M.P. and G.E. Mizon, 1991. Empirical Analysis of Macroeconomic Time Series-VAR and Structural models.European Economic Review, 35, pp. 887932.

Dickey, D. A. and W.A.Fuller, 1979. Distribution of the Estimators fora Autoregressive Time Series with a Unit Root. Journal of the American Statistical Association, 74, pp. 427-431.

Franses, Ph. H, P. Kofman and J. Moser, 1992. Garch effects on a test of cointegration. Mimeo, Erasmus University, Rotterdam.

Haldrup, N., 1992. Heteroscedasticity in Non-stationary Time Series. Memo 1992-8, University of Aarhus.

Hendry, D.F. and G.E. Mizon, 1990. Evaluating dynamic econometric models by encompassing the VAR, in P.C.B. Phillips and V.B. Hall, eds., Models, Methods, and applications of Econometrics, Essays in Honour of Rex Bergstrom.

Hendry, D.F. and A. Neale, 1990. The Impact of Structural Breaks on Unit Root Tests, in P. Hackl and A. Westlung, eds., Economic Structural Change: Analysis and Forecasting (IIASA and Springer-Verlag, Berlin).

Johansen, S., 1988. Statistical Analysis of Cointegration Vectors. Journal of Economic Dynamics and Control, 12, pp. 231-254.

Johansen, S., 1991. Estimation and Hypothesis Testing of Cointegration Vectors in Gaussian Vector Autoregressive Models. Econometrica, 59, pp. 1551-1580.

Johansen, S. and K. Juselius 1990. Maximum Likelihood Estimation and Inference on Cointegration-with Applications to the Demand for Money. Oxford Bulletin of Economics and Statistics, 52, pp. 169-210.

Kim, K. and P. Schmidt, 1991. Unit Root Tests with Conditional Heteroscedasticity. 
Mimeo, Michigan State University.

Ledolter, J., 1989. The Effects of Additive Outliers on the Forecasts from ARIMA Models. International Journal of Forecasting, 5, pp. 231-240.

Maravall, A. and D. Peña, 1992. Missing Observations and Additive Outliers in Time

Series Models, forthcoming Advances in Statistical Analysis and Statistical Computing. JAI-press.

Martin, R.D., and V.J. Yohai, 1986. Influence Functionals for Time Series. Annals of Statistics, 14, pp. 781-818.

Pantula, S., 1991. Asymptotic Distributions of Unit-Root Tests When the Process is Nearly Stationary. Journal of Business and Economic Statistics, Vol. 9, pp. 6371.

Perron, P., 1989. The Great Crash, the Oil Price Shock, and the Unit Root Hypothesis. Econometrica, 57, pp. 1361-1401.

Perron, P., 1990. Testing for a Unit Root in a Time Series With a Changing Mean. Journal of Business and Economic Statistics, 8, pp. 153-162.

Perron, P., and T. J. Vogelsang, 1992. Nonstationarity and Level Shifts with an Application to Purchasing Power Parity, Journal of Business and Economic Statistics, Vol. 10, pp. 301-320.

Phillips, P.C.B., 1987. Time Series Regression with a Unit Root. Econometrica, 55, pp. 277-302.

Rappoport P., and L. Reichlin, 1989. Segmented Trends and Non-Stationary Time Series.Economic Journal, 99, pp. 168-177.

Schwert, G.W., 1989. Tests for Unit Roots: A Monte Carlo Investigation. Journal of Business and Economic Statistics, 7, pp. 147-160.

Zivot, E., and W.K.Andrews, 1992. Further Evidence on the Great Crash, the OilPrice Shock, and the Unit-Root Hypothesis. Journal of Business and Economic Statistics, Vol. 10, pp. 251-270. 


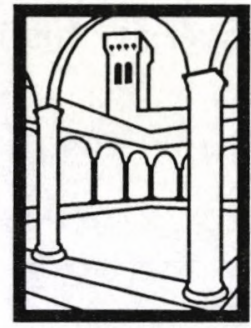

EUI

WORKING

PAPERS

EUI Working Papers are published and distributed by the

European University Institute, Florence

Copies can be obtained free of charge

- depending on the availability of stocks - from:

The Publications Officer

European University Institute

Badia Fiesolana

I-50016 San Domenico di Fiesole (FI)

Italy

Please use order form overleaf 


\section{Publications of the European University Institute}

To

The Publications Officer

European University Institute

Badia Fiesolana

I-50016 San Domenico di Fiesole (FI)

Italy

From

Name

Address.

$\square$ Please send me a complete list of EUI Working Papers

$\square$ Please send me a complete list of EUI book publications

$\square$ Please send me the EUI brochure Academic Year 1993/94

$\square$ Please send me the EUI Research Report

Please send me the following EUI Working Paper(s):

No, Author

Title:

No, Author

Title:

No, Author

Title:

No, Author

Title:

Date

Signature 


\section{Working Papers of the Department of Economics Published since 1990}

ECO No. 90/1

Tamer BASAR and Mark SALMON

Credibility and the Value of Information

Transmission in a Model of Monetary

Policy and Inflation

ECO No. 90/2

Horst UNGERER

The EMS - The First Ten Years

Policies - Developments - Evolution

ECO No. 90/3

Peter J. HAMMOND

Interpersonal Comparisons of Utility:

Why and how they are and should be made

ECO No. 90/4

Peter J. HAMMOND

A Revelation Principle for (Boundedly)

Bayesian Rationalizable Strategies

ECO No. $90 / 5$

Peter J. HAMMOND

Independence of Irrelevant Interpersonal Comparisons

ECO No. 90/6

Hal R. VARIAN

A Solution to the Problem of

Externalities and Public Goods when

Agents are Well-Informed

ECO No. 90/7

Hal R. VARIAN

Sequential Provision of Public Goods

ECO No. 90/8

T. BRIANZA, L. PHLIPS and J.F.

RICHARD

Futures Markets, Speculation and

Monopoly Pricing

ECO No. 90/9

Anthony B. ATKINSON/ John

MICKLEWRIGHT

Unemployment Compensation and

Labour Market Transition: A Critical

Review

ECO No. 90/10

Peter J. HAMMOND

The Role of Information in Economics
ECO No. 90/11

Nicos M. CHRISTODOULAKIS

Debt Dynamics in a Small Open

Economy

ECO No. 90/12

Stephen C. SMITH

On the Economic Rationale for

Codetermination Law

ECO No. 90/13

Elettra AGLIARDI

Learning by Doing and Market Structures

ECO No. 90/14

Peter J. HAMMOND

Intertemporal Objectives

ECO No. 90/15

Andrew EVANS/Stephen MARTIN

Socially Acceptable Distortion of

Competition: EC Policy on State Aid

ECO No. 90/16

Stephen MARTIN

Fringe Size and Cartel Stability

ECO No. 90/17

John MICKLEWRIGHT

Why Do Less Than a Quarter of the

Unemployed in Britain Receive

Unemployment Insurance?

ECO No. 90/18

Mrudula A. PATEL

Optimal Life Cycle Saving With

Borrowing Constraints:

A Graphical Solution

ECO No. 90/19

Peter J. HAMMOND

Money Metric Measures of Individual

and Social Welfare Allowing for

Environmental Externalities

ECO No. 90/20

Louis PHLIPS/

Ronald M. HARSTAD

Oligopolistic Manipulation of Spot

Markets and the Timing of Futures

Market Speculation 
ECO No. 90/21

Christian DUSTMANN

Earnings Adjustment of Temporary

Migrants

ECO No. 90/22

John MICKLEWRIGHT

The Reform of Unemployment

Compensation:

Choices for East and West

ECO No. 90/23

Joerg MAYER

U. S. Dollar and Deutschmark as

Reserve Assets

ECO No. 90/24

Sheila MARNIE

Labour Market Reform in the USSR:

Fact or Fiction?

ECO No. 90/25

Peter JENSEN/

Niels WESTERGÄRD-NIELSEN

Temporary Layoffs and the Duration of

Unemployment: An Empirical Analysis

ECO No. 90/26

Stephan L. KALB

Market-Led Approaches to European

Monetary Union in the Light of a Legal

Restrictions Theory of Money

ECO No. 90/27

Robert J. WALDMANN

Implausible Results or Implausible Data?

Anomalies in the Construction of Value

Added Data and Implications for Esti-

mates of Price-Cost Markups

ECO No. 90/28

Stephen MARTIN

Periodic Model Changes in Oligopoly

ECO No. 90/29

Nicos CHRISTODOULAKIS/

Martin WEALE

Imperfect Competition in an Open

Economy

\section{洸洸}

ECO No. 91/30

Steve ALPERN/Dennis J. SNOWER

Unemployment Through 'Learning From Experience'

ECO No. 91/31

David M. PRESCOTT/Thanasis

STENGOS

Testing for Forecastible Nonlinear

Dependence in Weekly Gold Rates of Return

ECO No. 91/32

Peter J. HAMMOND

Harsanyi's Utilitarian Theorem:

A Simpler Proof and Some Ethical Connotations

ECO No. 91/33

Anthony B. ATKINSON/

John MICKLEWRIGHT

Economic Transformation in Eastern

Europe and the Distribution of Income*

ECO No. 91/34

Svend ALBAEK

On Nash and Stackelberg Equilibria

when Costs are Private Information

ECO No. 91/35

Stephen MARTIN

Private and Social Incentives

to Form R \& D Joint Ventures

ECO No. 91/36

Louis PHLIPS

Manipulation of Crude Oil Futures

ECO No. 91/37

Xavier CALSAMIGLIA/Alan KIRMAN

A Unique Informationally Efficient and

Decentralized Mechanism With Fair

Outcomes

ECO No. 91/38

George S. ALOGOSKOUFIS/

Thanasis STENGOS

Testing for Nonlinear Dynamics in

Historical Unemployment Series

ECO No. 91/39

Peter J. HAMMOND

The Moral Status of Profits and Other

Rewards:

A Perspective From Modern Welfare

Economics 
ECO No. 91/40

Vincent BROUSSEAU/Alan KIRMAN

The Dynamics of Learning in Mis-

Specified Models

ECO No. 91/41

Robert James WALDMANN

Assessing the Relative Sizes of Industryand Nation Specific Shocks to Output

ECO No. 91/42

Thorsten HENS/Alan KIRMAN/Louis PHLIPS

Exchange Rates and Oligopoly

ECO No. 91/43

Peter J. HAMMOND

Consequentialist Decision Theory and

Utilitarian Ethics

ECO No. 91/44

Stephen MARTIN

Endogenous Firm Efficiency in a Cournot

Principal-Agent Model

ECO No. 91/45

Svend ALBAEK

Upstream or Downstream Information Sharing?

ECO No. 91/46

Thomas H. McCURDY/

Thanasis STENGOS

A Comparison of Risk-Premium

Forecasts Implied by Parametric Versus

Nonparametric Conditional Mean

Estimators

ECO No. 91/47

Christian DUSTMANN

Temporary Migration and the Investment into Human Capital

ECO No. 91/48

Jean-Daniel GUIGOU

Should Bankruptcy Proceedings be

Initiated by a Mixed

Creditor/Shareholder?

ECO No. 91/49

Nick VRIEND

Market-Making and Decentralized Trade

ECO No. 91/50

Jeffrey L. COLES/Peter J. HAMMOND

Walrasian Equilibrium without Survival:

Existence, Efficiency, and Remedial

Policy
ECO No. 91/51

Frank CRITCHLEY/Paul MARRIOTT/

Mark SALMON

Prelerred Point Geometry and Statistical Manifolds

\section{ECO No. 91/52}

Costanza TORRICELLI

The Influence of Futures on Spot Price Volatility in a Model for a Storable Commodity

ECO No. 91/53

Frank CRITCHLEY/Paul MARRIOTT/ Mark SALMON

Preferred Point Geometry and the Local Differential Geometry of the Kullback-

Leibler Divergence

ECO No. 91/54

Peter MØLLGAARD/

Louis PHLIPS

Oil Futures and Strategic

Stocks at Sea

ECO No. 91/55

Christian DUSTMANN/

John MICKLEWRIGHT

Benefits, Incentives and Uncertainty

ECO No. 91/56

John MICKLEWRIGHT/

Gianna GIANNELLI

Why do Women Married to Unemployed

Men have Low Participation Rates?

ECO No. 91/57

John MICKLEWRIGHT

Income Support for the Unemployed in Hungary

ECO No. 91/58

Fabio CANOVA

Detrending and Business Cycle Facts

ECO No. 91/59

Fahio CANOVA/

Jane MARRINAN

Reconciling the Term Structure of

Interest Rates with the Consumption

Based ICAP Model

ECO No. 91/60

John FINGLETON

Inventory Holdings by a Monopolist Middleman 
米深米

ECO No. 92/61

Sara CONNOLLY/John

MICKLEWRIGHT/Stephen NICKELL

The Occupational Success of Young Men

Who Left School at Sixteen

ECO No. 92/62

Pier Luigi SACCO

Noise Traders Permanence in Stock

Markets: A Tâtonnement Approach.

I: Informational Dynamics for the Two-

Dimensional Case

ECO No. 92/63

Robert J. WALDMANN

Asymmetric Oligopolies

ECO No. 92/64

Robert J. WALDMANN/Stephen

C. SMITH

A Partial Solution to the Financial Risk and Perverse Response Problems of Labour-Managed Firms: Industry-

Average Performance Bonds

ECO No. 92/65

Agustín MARAVALL/Víctor GÓMEZ

Signal Extraction in ARIMA Time Series

Program SEATS

ECO No. 92/66

Luigi BRIGHI

A Note on the Demand Theory of the

Weak Axioms

ECO No. 92/67

Nikolaos GEORGANTZIS

The Effect of Mergers on Potential

Competition under Economies or

Diseconomies of Joint Production

ECO No. 92/68

Robert J. WALDMANN/

J. Bradford DE LONG

Interpreting Procyclical Productivity:

Evidence from a Cross-Nation CrossIndustry Panel

ECO No. 92/69

Christian DUSTMANN/John

MICKLEWRIGHT

Means-Tested Unemployment Benefit

and Family Labour Supply: A Dynamic

Analysis
ECO No. 92/70

Fabio CANOVAVBruce E. HANSEN

Are Seasonal Patterns Constant Over

Time? A Test for Seasonal Stability

ECO No. 92/71

Alessandra PELLONI

Long-Run Consequences of Finite

Exchange Rate Bubbles

ECO No. $92 / 72$

Jane MARRINAN

The Effects of Government Spending on Saving and Investment in an Open

Economy

ECO No. 92/73

Fubio CANOVA and Jane MARRINAN Profits, Risk and Uncertainty in Foreign

Exchange Markets

ECO No. 92/74

Louis PHLIPS

Basing Point Pricing, Competition and

Market Integration

ECO No. 92/75

Stephen MARTIN

Economic Efficiency and Concentration:

Are Mergers a Fitting Response?

ECO No. $92 / 76$

Luisa ZANCHI

The Inter-Industry Wage Structure:

Empirical Evidence for Germany and a

Comparison With the U.S. and Sweden

ECO NO. 92/77

Agustín MARAVALL

Stochastic Linear Trends: Models and

Estimators

ECO No. 92/78

Fabio CANOVA

Three Tests for the Existence of Cycles in Time Series

ECO No. 92/79

Peter J. HAMMOND/Jaime SEMPERE

Limits to the Potential Gains from Market

Integration and Other Supply-Side

Policies 
ECO No. 92/80

Víctor GÓMEZ and Agustín

MARAVALL

Estimation, Prediction and Interpolation

for Nonstationary Series with the

Kalman Filter

ECO No. 92/81

Víctor GÓMEZ and Agustín

MARAVALL

Time Series Regression with ARIMA

Noise and Missing Observations

Program TRAM

ECO No. 92/82

J. Bradford DE LONG/ Marco BECHT

"Excess Volatility" and the German

Stock Market, 1876-1990

ECO No. 92/83

Alan KIRMAN/Louis PHLIPS

Exchange Rate Pass-Through and Market

Structure

ECO No. 92/84

Christian DUSTMANN

Migration, Savings and Uncertainty

ECO No. 92/85

J. Bradford DE LONG

Productivity Growth and Machinery

Investment: A Long-Run Look, 187()1980)

ECO NO. 92/86

Robert B. BARSKY and J. Bradford

DE LONG

Why Does the Stock Market Fluctuate?

ECO No. 92/87

Anthony B. ATKINSON/John

MICKLEWRIGHT

The Distribution of Income in Eastern

Europe

\section{ECO No.92/88}

Agustín MARAVALUAlexandre

MATHIS

Encompassing Unvariate Models in

Multivariate Time Series: A Case Study

ECO No. 92/89

Peter J. HAMMOND

Aspects of Rationalizable Behaviour
ECO 92/90

Alan P. KIRMAN/Robert

J. WALDMANN

I Quit

ECO No. 92/91

Tilman EHRBECK

Rejecting Rational Expectations in Panel

Data: Some New Evidence

ECO No. 92/92

Djordje Suvakovic OLGIN

Simulating Codetermination in a

Cooperative Economy

ECO No. 92/93

Djordje Suvakovic OLGIN

On Rational Wage Maximisers

ECO No. 92/94

Christian DUSTMANN

Do We Stay or Not? Return Intentions of

Temporary Migrants

ECO No. 92/95

Djordje Suvakovic OLGIN

A Case for a Well-Defined Negative

Marxian Exploitation

ECO No. 92/96

Sarah J. JARVIS/John

MICKLEWRIGHT

The Targeting of Family Allowance in Hungary

ECO No. 92/97

Agustín MARAVALL/Daniel PEÑA

Missing Observations and Additive

Outliers in Time Series Models

ECO No. 92/98

Marco BECHT

Theory and Estimation of Individual and

Social Welfare Measures: A Critical

Survey

ECO No. 92/99

Louis PHLIPS and Ireneo Miguel

MORAS

The AKZO Decision: A Case of

Predatory Pricing?

ECO No. 92/100

Stephen MARTIN

Oligopoly Limit Pricing With Firm-

Specific Cost Uncertainty 
ECO No. 92/101

Fabio CANOVA/Eric GHYSELS

Changes in Seasonal Patterns: Are They

Cyclical?

ECO No. 92/102

Fabio CANOVA

Price Smoothing Policies: A Wellare

Analysis

深棌

ECO No. 93/1

Carlo GRILLENZONI

Forecasting Unstable and Non-Stationary

Time Series

ECO No. 93/2

Carlo GRILLENZONI

Multilinear Models for Nonlinear Time

Series

ECO No. 93/3

Ronald M. HARSTAD/Louis PHLIPS

Futures Market Contracting When You

Don't Know Who the Optimists Are

ECO No. 93/4

Alan KIRMAN/Louis PHLIPS

Empirical Studies of Product Markets

ECO No. 93/5

Grayham E. MIZON

Empirical Analysis of Time Series:

Illustrations with Simulated Data

ECO No. 93/6

Tilman EHRBECK

Optimally Combining Individual

Forecasts From Panel Data

ECO NO. 93/7

Víctor GÓMEZ/Agustín MARAVALL

Initializing the Kalman Filter with

Incompletely Specified Initial Conditions

ECO No. 93/8

Frederic PALOMINO

Informed Speculation: Small Markets

Against Large Markets

ECO NO. 93/9

Stephen MARTIN

Beyond Prices Versus Quantities
ECO No. 93/10

José María LABEAGA/Angel LÓPEZ

A Flexible Demand System and VAT

Simulations from Spanish Microdata

ECO No. 93/11

Maozu LU/Grayham E. MIZON

The Encompassing Principle and

Specification Tests

ECO No. 93/12

Louis PHLIPS/Peter MØLLGAARD

Oil Stocks as a Squeeze Preventing

Mechanism: Is Self-Regulation Possible?

ECO No. 93/13

Pieter HASEKAMP

Disinflation Policy and Credibility: The

Role of Conventions

ECO No. 93/14

Louis PHLIPS

Price Leadership and Conscious

Parallelism: A Survey

ECO No. 93/15

Agustín MARAVALL

Short-Term Analysis of Macroeconomic

Time Series

ECO No. 93/16

Philip Hans FRANSES/Niels

HALDRUP

The Effects of Additive Outliers on Tests for Unit Roots and Cointegration 



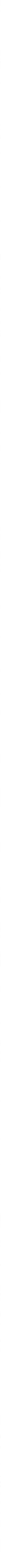

